Check for updates

Cite this: RSC Adv., 2017, 7, 44178

Received 22nd July 2017

Accepted 6th September 2017

DOI: $10.1039 / c 7 r a 08097 b$

rsc.li/rsc-advances

\section{Aconitic acid derived carbon dots as recyclable "on-off-on" fluorescent nanoprobes for sensitive detection of mercury(II) ions, cysteine and cellular imaging $\dagger$}

\author{
Fengjiao Zhao, ${ }^{\mathrm{a}}$ Jiali Qian, ${ }^{\mathrm{a}}$ Feifei Quan, ${ }^{\mathrm{a}}$ Chengxin Wu, ${ }^{\mathrm{a}}$ Yian Zheng (D) ${ }^{\mathrm{b}}$ \\ and Lei Zhou (DD *a
}

In this study, aconitic acid (AA) was applied as a new carbon precursor for the fabrication of fluorescent carbon dots (CDs) using a facile one-step microwave-assisted synthesis approach with ethylenediamine as the co-doping reagent. The AA derived CDs (AA-CDs) were water-soluble and the aqueous solution of AA-CDs exhibited excitation-independent, bright blue fluorescence with an absolute quantum yield of $45.1 \%$. Without further surface modification, the intrinsic fluorescence can be gradually quenched by the incremental addition of $\mathrm{Hg}^{2+}$ ions through an effective electron or energy transfer process due to the high affinity of $\mathrm{Hg}^{2+}$ to $\mathrm{AA}-\mathrm{CD}$. By introducing cysteine (Cys) into the $\mathrm{AA}-\mathrm{CDs}-\mathrm{Hg}^{2+}$ system, the quenched fluorescence will be recovered via the formation of $\mathrm{Hg}-\mathrm{S}$ bonds, which can be utilized to further enhance the selectivity for sensing $\mathrm{Hg}^{2+}$ ions. Based on the "on-off-on" system, we established a sensitive and selective fluorescence sensor for turn-off detection of $\mathrm{Hg}^{2+}$ ions and turn-on detection of Cys in aqueous solution, with detection limits of 5.5 and $30 \mathrm{nM}$, respectively. The fluorescence of $\mathrm{AA}-\mathrm{CDs}$ could be repeatedly turned off and on for over 10 cycles by alternately adding $\mathrm{Hg}^{2+}$ ions and Cys, suggesting excellent reversibility. Furthermore, the prepared AA-CDs were successfully applied for the determination of $\mathrm{Hg}^{2+}$ in environmental water samples, and also as fluorescent nanoprobes for imaging $\mathrm{Hg}^{2+}$ ions and Cys in living cells.

\section{Introduction}

Nanoscale materials, benefiting from their versatile structures and functions, have received intense attention and offer promising applications in both research and practice for analytical science. ${ }^{\mathbf{1 - 4}}$ As an emerging fluorescent carbon nanomaterial, carbon dots (CDs) possess some distinct features such as excellent optical properties, chemical stability, biocompatibility, and low toxicity, ${ }^{5-8}$ which enable them to be widely used in different fields including bioimaging, medical diagnosis, catalysis, photovoltaic devices, and so on ${ }^{6-15}$ Generally, CDs can interact with analytes to facilitate the non-radiative electron/ hole recombination and annihilation via electron or energy transfer processes, resulting in either enhancement or quenching in the intrinsic fluorescence of CDs for subsequent qualitative or quantitative analysis. Depending on different

${ }^{a}$ State Key Laboratory of Applied Organic Chemistry, College of Chemistry and Chemical Engineering, Lanzhou University, Lanzhou 730000, China. E-mail: zhoulei1@lzu.edu.cn

${ }^{b}$ Gansu Key Laboratory for Environmental Pollution Prediction and Control, College of Earth and Environmental Sciences, Lanzhou University, Lanzhou 730000, China

$\dagger$ Electronic supplementary information (ESI) available. See DOI: 10.1039/c7ra08097b carbon source and synthesis methods, CDs usually contain some functional groups such as carboxyl, amino, and/or mercapto groups, etc., and accordingly their inherent fluorescence could be easily quenched by some electron acceptors in solution. Consequently, CDs were usually applied as fluorescent nanoprobes for the detection of metal ions. ${ }^{16-18}$

As one of the most toxic chemicals, $\mathrm{Hg}^{2+}$ ions have severe adverse effects on human health and environment safety. Given their persistence, easy mobility and bioaccumulation, $\mathrm{Hg}^{2+}$ ions have become one of the most important heavy metal pollutants throughout the world. ${ }^{19}$ Therefore, developing new methods and strategies for the detection of $\mathrm{Hg}^{2+}$ ions in environment and biological samples are of continuous interests in analytical chemistry. ${ }^{20-22}$ As strong electron acceptor, $\mathrm{Hg}^{2+}$ ions are easily bound onto the surface of CDs through the electrostatic and/or coordination interactions, resulting in significant fluorescence quenching. Based on this, several CDs have been utilized as fluorescent probes for the detection of $\mathrm{Hg}^{2+}$ ions in different samples. ${ }^{23-39}$ Among these studies, quenching mode has been employed for the quantitative analysis of $\mathrm{Hg}^{2+}$ ions. However, the quenching mode is usually subjected to poor selectivity from uncertain factors affecting fluorescence quenching. It is well known that $\mathrm{Hg}^{2+}$ ions could exhibit strong interaction with 
mercapto groups to form $\mathrm{Hg}-\mathrm{S}$ bonds, and as a consequence, the mercapto compounds were commonly used in some sensing systems to recover the quenched fluorescence by $\mathrm{Hg}^{2+}$ ions. The so-called "on-off-on" sensing strategy greatly improves the selectivity for the detection of $\mathrm{Hg}^{2+}$ ions, and meanwhile, this principle could be applied to establish new analytical methods for the determination of some important mercapto-containing biomolecules. Recently, some studies have been reported using $\mathrm{Hg}^{2+}$-quenched CDs as probes for the detection of mercapto biomolecules such as cysteine (Cys). ${ }^{\mathbf{4 0 - 4 7}}$ Nevertheless, there are still considerable problems to be investigated in these studies. For instance, $\mathrm{Hg}^{2+}$ ions served only as an intermediate to quench the fluorescence of CDs whereas their analysis was ignored; the quantum yield of CDs was too low to improve the detection sensitivity; and the selectivity of the developed method had yet to be further improved.

In previous studies, the researchers had obtained fluorescent CDs with high quantum yield using citric acid as carbon precursor. ${ }^{4-51}$ Aconitic acid (AA) has a similar structure with citric acid, and its molecular skeleton contains one ethylenic bond, so we speculate it to be a more ideal precursor for the preparation of CDs. In this study, AA as a new carbon precursor was used for the preparation of CDs by a facile, one-step microwave-assisted method. The resulting AA-CDs were watersoluble, and emitted excitation-independent, bright blue fluorescence with high absolute quantum yield of $45.1 \%$. Without further surface modification, $\mathrm{Hg}^{2+}$ ions could effectively quench the fluorescence of AA-CDs with excellent selectivity. By introducing Cys into this $\mathrm{AA}-\mathrm{CDs}-\mathrm{Hg}^{2+}$ system, the previously quenched fluorescence would be recovered, which could be utilized to further enhance the selectivity of $\mathrm{Hg}^{2+}$ ions sensor. Subsequently, we established a sensitive analytical method to detect $\mathrm{Hg}^{2+}$ ions and Cys in aqueous solution. Moreover, the asprepared $\mathrm{AA}-\mathrm{CDs}$ and $\mathrm{AA}-\mathrm{CDs}-\mathrm{Hg}^{2+}$ system were applied as fluorescent nanoprobes to facilitate label-free intracellular imaging of $\mathrm{Hg}^{2+}$ ions and Cys in living cells.

\section{Experimental}

\subsection{Chemicals}

Aconitic acid (AA) was of analytical reagent grade and purchased from Alfa Aesar Chemistry (Tianjin, China). 1,2-Ethylenediamine (EDA, analytical reagent grade) was obtained from Baishi Chemical Reagent (Tianjin, China). 4-(2-Hydroxyethyl)-1piperazineethanesulfonic acid (HEPES) was received from Sigma-Aldrich. Twenty amino acids including alanine (Ala), arginine (Arg), asparagine (Asn), aspartic acid (Asp), cysteine (Cys), glutamine (Gln), glutamic acid (Glu), glycine (Gly), histidine (His), isoleucine (Ile), leucine (Leu), lysine (Lys), methionine (Met), proline (Pro), phenylalanine (Phe), serine (Ser), threonine (Thr), tryptophane (Trp), tyrosine (Tyr), valine (Val), were all of analytical reagent grade and purchased from Xi'an Zhoudingguo Biotech (China). All metal salts were of analytical grade and dissolved in ultrapure water. All chemicals were used as received without further purification.

\subsection{Apparatus and characterization}

All fluorescence spectra were surveyed on an F97Pro fluorospectrophotometer (Lengguang Technology, Shanghai, China) using $10.0 \mathrm{~nm}$ slit width for both excitation and emission, and equipped with a $10 \mathrm{~mm} \times 10 \mathrm{~mm}$ quartz cuvette. The ultraviolet-visible (UV-vis) absorption spectra were recorded using a UV 2800SPC spectrophotometer (Sunny Hengping Scientific Instrument, Shanghai, China) with a $10 \mathrm{~mm}$ path length quartz cell. The fluorescence quantum yield (QY) of AA-CDs was determined by absolute method (called absolute QY) using an FLS920 spectrometer (Edinburgh Instruments, U.K.) and the integrating sphere accessory. For the determination of absolute QY, only dilute solutions and the corresponding solvent at the excitation wavelength $\left(\lambda_{\mathrm{ex}}=360 \mathrm{~nm}\right)$ were used. Time-resolved fluorescence spectra were carried out in a timecorrelated single photon counting (TCSPC) system from FLS920 spectrometer with $\lambda_{\mathrm{ex}}=360 \mathrm{~nm}$ and $\lambda_{\mathrm{em}}=450 \mathrm{~nm}$ (the details are given in ESI $\dagger$ ). The morphologies of AA-CDs were observed by transmission electron microscopy (TEM, Tecnai F30, FEI, Netherlands), with an accelerating voltage of $200 \mathrm{kV}$. The sample for TEM observation was made by dropping AA-CDs solution onto 300-mesh copper grids coated with a lacy carbon film. The particle size distribution was measured on a BI-200SM dynamic light scattering (DLS) instrument (Brookhaven, USA). The elemental analyses (C, $\mathrm{H}$ and $\mathrm{N}$ ) were performed on a Vario EL elemental analyzer (Elementar, Germany). The surface functional groups of AA-CDs were investigated by X-ray photoelectron spectroscopy (XPS, PHI 5702, PerkinElmer) equipped with an $\mathrm{Al} \mathrm{K} \alpha$ exciting source and Fourier transform infrared spectra (FT-IR, NEXUS 670 spectrometer, Nicolet) from 4000 to $400 \mathrm{~cm}^{-1}$ using $\mathrm{KBr}$ pellets, respectively. The zeta potential of AA-CDs in HEPES buffer was measured using Malvern Zetasizer $3000 \mathrm{HSa}$ (He-Ne laser, $\lambda=632.8 \mathrm{~nm}$ ).

\subsection{Microwave-assisted synthesis of AA-CDs}

Typically, $0.0871 \mathrm{~g}$ AA and $100.4 \mu \mathrm{L}$ of EDA were dissolved in $5 \mathrm{~mL}$ ultrapure water to form a homogeneous solution. Then, the solution was put into a domestic microwave oven (Midea, China) and radiated for $6 \mathrm{~min}$ at $700 \mathrm{~W}$, with the change of the solution from original colorless liquid to golden-yellow solid, indicating the formation of AA-CDs. The golden-yellow solid was then dried at $50{ }^{\circ} \mathrm{C}$ for $2 \mathrm{~h}$ in vacuum oven. After completely dried, the solid was ground into uniform powder and stored for further use. The AA-CDs powder can be easily dispersed in water to reconstruct stable solution.

\subsection{On-off-on sensor for $\mathrm{Hg}^{2+}$ ions and $\mathrm{Cys}$}

For the fluorescence on-off-on sensing experiments, an appropriate amount $\left(20 \mu \mathrm{g} \mathrm{mL}^{-1}\right)$ of AA-CDs was dissolved in $3 \mathrm{~mL}$ HEPES buffer (10 mM). For the turn-off sensor, various concentrations of $\mathrm{Hg}^{2+}$ ions up to $20 \mu \mathrm{M}$ were gradually added into the AA-CDs solution to quench their fluorescence. For the turn-on sensor, different amounts of Cys were added into the non-fluorescence AA-CDs- $\mathrm{Hg}^{2+}$ system (adding $20 \mu \mathrm{M} \mathrm{Hg}{ }^{2+}$ ions into AA-CDs solution in advance) to recover their 
fluorescence. The selectivity measurements were investigated for $\mathrm{Hg}^{2+}$ ions and Cys using common metal ions and other 19 amino acids, respectively. Subsequently, the reversibility of the "on-off-on" fluorescence sensor was tested by adding $\mathrm{Hg}^{2+}$ ions and Cys alternately. All of the experiments were carried out at room temperature, and the excitation and emission wavelengths were fixed at 360 and $450 \mathrm{~nm}$, respectively.

Further, three water samples were collected to assess the applicability of AA-CDs for $\mathrm{Hg}^{2+}$ detection in real environmental samples, including tap water (from our lab), lake water (from the lake in the campus of Lanzhou University), and river water (from the Yellow River in Lanzhou section). All water samples were naturally settled for $24 \mathrm{~h}$, and then centrifuged for $10 \mathrm{~min}$ at $10000 \mathrm{rpm}$. Subsequently, the supernatant was filtered through a $0.45 \mu \mathrm{m}$ pore size cellulose acetate membrane filter before analysis.

\subsection{Fluorescence imaging in living cells}

The SMMC-7721 hepatoma cells, obtained from the Institute of Cell Biology (Shanghai, China), were seeded in 12-well plates (1 mL per well) and cultured using Roswell Park Memorial Institute-1640 (RPMI-1640) supplemented with 5\% fetal bovine serum (FBS), $1 \%$ streptomycin at $37{ }^{\circ} \mathrm{C}$ in a humidified atmosphere of $5 \% \mathrm{CO}_{2}$ overnight. After adding proper concentrations of AA-CDs $\left(200 \mu \mathrm{g} \mathrm{mL}{ }^{-1}\right), \mathrm{AA}-\mathrm{CDs}-\mathrm{Hg}^{2+}\left(100 \mu \mathrm{M}\right.$ for $\left.\mathrm{Hg}^{2+}\right)$, and Cys $(150 \mu \mathrm{M})$, the 12 -well plates were put back to incubator for $1 \mathrm{~h}$ at $37^{\circ} \mathrm{C}$. After that, remove the incubation media and rinse with new culture media. And then, the cells incubated by AA-CDs was further incubated for another $30 \mathrm{~min}$ at $37^{\circ} \mathrm{C}$ using $\mathrm{Hg}^{2+}$ ions $(100 \mu \mathrm{M})$ and the cells incubated with $\mathrm{AA}-\mathrm{CDs}-\mathrm{Hg}^{2+}$ was further incubated for another $1 \mathrm{~h}$ using Cys $(150 \mu \mathrm{M})$. Prior to fixation of the cells on the slide for inspection, the excess culture media were removed by washing three times with phosphate buffer solution (PBS, $10 \mathrm{mM}, \mathrm{pH}$ 7.4). Afterwards, the fluorescence images were taken on an Olympus FV-1000 laser confocal microscope (Japan) with $405 \mathrm{~nm}$ laser.

\section{Results and discussion}

\subsection{Characterization of AA-CDS}

Aconitic acid is speculated to be an ideal precursor to produce CDs due to its unsaturated bond that may give more possibilities to generate excellent optical properties. As expected, the obtained AA-CDs exhibited strong blue fluorescence under UV light (365 nm, inset in Fig. 1). Further, the optical properties of the prepared AA-CDs were confirmed by UV-vis absorption and fluorescence spectra in aqueous solution. As shown in Fig. 1, the AA-CDs solution exhibited an absorption at about $340 \mathrm{~nm}$ in UV-vis spectrum, which was ascribed to the $n-\pi *$ transition of the AA-CDs. ${ }^{52}$ The fluorescence spectra showed that the optimum emission of AA-CDs was peaked at $450 \mathrm{~nm}$ when excited at $360 \mathrm{~nm}$. By consecutively altering the excitation wavelengths from 300 to $380 \mathrm{~nm}$, no obvious wavelength shift was observed in the fluorescence emission spectra of AA-CDs, demonstrating an excitation-independent fluorescence behavior. The absolute QY of AA-CDs was measured to be

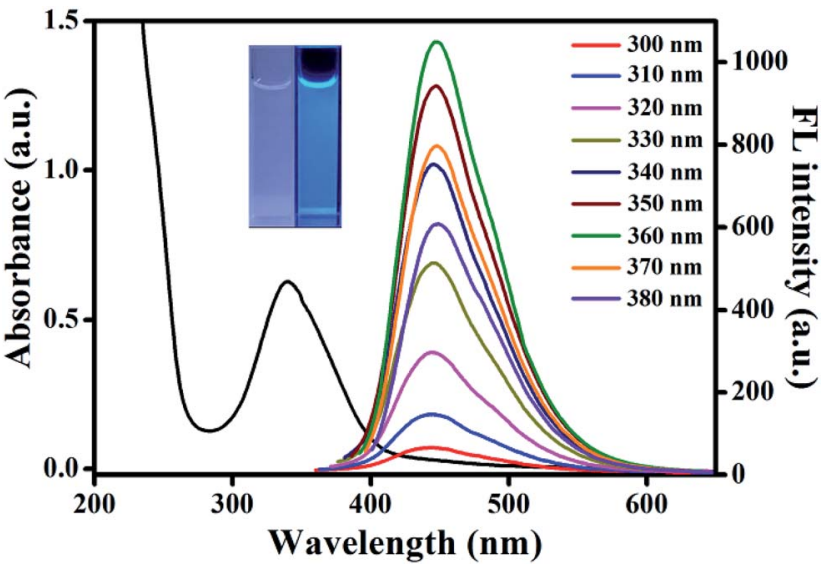

Fig. 1 UV-vis absorption (black line) and fluorescent emission spectra of AA-CDs under various excitation wavelengths from 300 to $380 \mathrm{~nm}$. Inset: photographs of AA-CDs under daylight (left) and UV lamp (right, $365 \mathrm{~nm}$ ).

45.1\%, which was competent for acting as a highly sensitive sensor.

The morphology of the prepared AA-CDs was characterized by TEM and the results showed that the AA-CDs were well mono-dispersed and uniform in size (Fig. S1a $\dagger$ ). Dynamic light scattering analysis revealed that the size of AA-CDs was distributed in the range of 1.8 to $4.0 \mathrm{~nm}$ with an average size of $2.9 \mathrm{~nm}$ (Fig. S1b $\dagger$ ). Further elemental analysis indicated that the prepared AA-CDs were mainly composed of carbon $(45.36 \%)$, hydrogen (6.34\%), nitrogen (19.19\%), and oxygen $(29.11 \%$, calculated value).

The FTIR spectrum was acquired to identify the surface functional groups of the prepared AA-CDs (Fig. S2 $\dagger$ ). The absorption band at $3429.7 \mathrm{~cm}^{-1}$ is ascribed to the stretching vibration of $\mathrm{N}-\mathrm{H}$, and the bands at 3250 and $1146.1 \mathrm{~cm}^{-1}$ are attributed to the characteristic absorption of $\mathrm{O}-\mathrm{H}$ and $\mathrm{C}-\mathrm{O}$, respectively. The band at $2928.8 \mathrm{~cm}^{-1}$ can be assigned to the $\mathrm{C}-\mathrm{H}$ stretching vibration and the characteristic absorption band of $\mathrm{C}=\mathrm{O}$ and/or $\mathrm{C}=\mathrm{C}$ stretching vibration at around $1668.6 \mathrm{~cm}^{-1}$ is also observed. The bands at 1581.3 and $1358.5 \mathrm{~cm}^{-1}$ indicate the existence of $-\mathrm{COOH}{ }^{43,53}$ The surface composition for AA-CDs was further characterized by XPS, and the survey spectra presented three peaks for AA-CDs at around $285 \mathrm{eV}, 399.5 \mathrm{eV}$ and $531 \mathrm{eV}$, corresponding to $\mathrm{C} 1 \mathrm{~s}, \mathrm{~N} 1 \mathrm{~s}$ and $\mathrm{O}$ 1s, respectively (Fig. S3a $\dagger$ ). The high resolution XPS spectrum of $\mathrm{C} 1 \mathrm{~s}$ (Fig. $\mathrm{S} 3 \mathrm{~b} \dagger$ ) can be resolved into three peaks with $\mathrm{C}-\mathrm{C} / \mathrm{C}=\mathrm{C}$ at $284.8 \mathrm{eV}, \mathrm{C}-\mathrm{N} / \mathrm{C}-\mathrm{O}$ at $285.9 \mathrm{eV}$ and $\mathrm{C}=\mathrm{O}$ at $287.7 \mathrm{eV}$, respectively. The fitting of the $\mathrm{N}$ 1s peak (Fig. S3c $\dagger$ ) gives four components at $399.3 \mathrm{eV}, 399.7 \mathrm{eV}, 400.1 \mathrm{eV}$ and $401.5 \mathrm{eV}$, corresponding to $\mathrm{C}-\mathrm{N} / \mathrm{C}=\mathrm{N}$, pyrrole $\mathrm{N}$, pyrrolic $\mathrm{N}$ and $\mathrm{N}-\mathrm{H}$ bonds, respectively. Deconvolution of the $\mathrm{O} 1 \mathrm{~s}$ spectrum in Fig. $\mathrm{S} 3 \mathrm{~d} \dagger$ shows three peaks at $530.5 \mathrm{eV}, 531.0 \mathrm{eV}$ and $532.3 \mathrm{eV}$ for $\mathrm{C}=\mathrm{O}$, $\mathrm{C}-\mathrm{O}-\mathrm{C}$ and $\mathrm{C}-\mathrm{OH}$ groups, respectively. ${ }^{33,43}$ These findings suggest that the surface of AA-CDs is functionalized with amino, hydroxyl and carboxylic/carbonyl moieties originated from AA and EDA, which agrees well with the above FTIR results. In addition, the zeta potential of AA-CDs in HEPES 
buffer was measured to be $-6.23 \mathrm{mV}$, indicating its negativecharged surface.

In order to evaluate the feasibility for practical sensing applications, the prepared AA-CDs were investigated on its response towards ambient environments. Above all, the AA-CDs were inherently water-soluble because of the hydrophilic groups on the surface, and emitted stronger fluorescence in water compared to other common solvents (Fig. S4a†). Also, the fluorescence intensity had no obvious decrease even after light illumination $\left(\lambda_{\mathrm{ex}}=360 \mathrm{~nm}\right)$ for $7 \mathrm{~h}$, suggesting good photostability of the AA-CDs (Fig. S4b $\uparrow$ ). When the solid powder and solution of AA-CDs were stored for three months, no appreciable changes in the fluorescence intensity were observed, indicating excellent storage stability of the AA-CDs. External pH and ionic strengths are important factors affecting the fluorescence property of CDs. Fig. S4c $\dagger$ revealed that the fluorescence intensity showed a monotonic increase with increasing $\mathrm{pH}$ from 1.0 to 5.0, followed by a strong and stable signal from pH 5.0 to 10.0 , and then a monotonic decrease after $\mathrm{pH} 10.0$, which is closely correlated to the $\mathrm{pH}$-dependent nature of hydroxyl and carboxylic/carbonyl moieties attached onto the AA-CDs. Ionic strength had almost no influence on the fluorescence intensity of AA-CDs, even under the extreme condition of $3 \mathrm{~mol} \mathrm{~L}^{-1} \mathrm{NaCl}$ solution (Fig. S4d†). Based on above discussions, the prepared AA-CDs are particularly suitable as fluorescent nanoprobes for sensing applications under physiological conditions.

\subsection{Turn-off sensor for $\mathbf{H g}^{2+}$ ions}

Initially, we investigated the response of common metal ions on the fluorescence of AA-CDs, and the results indicated that the AA-CDs' fluorescence could be effectively quenched by mercury(II) ions, demonstrating that the prepared AA-CDs could serve as fluorescent nanoprobes for $\mathrm{Hg}^{2+}$ ions via turn-off mode. Fig. 2a showed the fluorescence spectra of the AA-CDs after adding various concentrations of $\mathrm{Hg}^{2+}$ ions $(0-20 \mu \mathrm{M})$, and a gradual decrease in PL intensity at $450 \mathrm{~nm}\left(\lambda_{\text {ex }}=360 \mathrm{~nm}\right)$ with increasing $\mathrm{Hg}^{2+}$ ions concentration was observed, revealing that the fluorescence intensity of AA-CDs was sensitive to $\mathrm{Hg}^{2+}$ ions concentration. The quenching efficiency $\left(F_{0} / F\right)$ displayed a parabolic increase versus the concentration of $\mathrm{Hg}^{2+}$ ions, where $F_{0}$ and $F$ are fluorescence intensities at $450 \mathrm{~nm}$ in the absence and presence of $\mathrm{Hg}^{2+}$, respectively. And in the lower concentration range of $0-50 \mathrm{nM}$, a good linear relationship was obtained with the correlation coefficient $(R)$ of 0.99 (Fig. S5†). The detection limit was estimated to be $5.5 \mathrm{nM}$ according to a signal-to-noise ratio of 3 , which was superior or comparable to other CDs sensing systems (Table S1†) and lower than the maximum level (10 $\mathrm{nM}, 2 \mathrm{ppb})$ for $\mathrm{Hg}^{2+}$ ions in drinking water mandated by the United States Environmental Protection Agency (EPA). ${ }^{54}$ Generally for a sensor, there are not only in the aspect of sensitivity but more importantly in the aspect of selectivity. Consequently, the selectivity and competition experiments were conducted, and it is clearly observed from Fig. 2b that except for $\mathrm{Hg}^{2+}$, the fluorescence intensity of AACDs showed no significant decrease by introducing other counter ions with the concentration of $60 \mu \mathrm{M}$, even in the mixed solution containing other 18 metal ions. The outstanding sensitivity and selectivity demonstrated the feasibility of AACDs as fluorescent nanoprobe for sensing $\mathrm{Hg}^{2+}$ ions in aqueous solution.

Then, the prepared AA-CDs were attempted to analyze $\mathrm{Hg}^{2+}$ ions in environmental water samples, including tap water, lake water, and river water. However, no detectable amount of $\mathrm{Hg}^{2+}$ ions was found in these water samples. Thus, the standard addition methodology with three spiked levels (10 nM, $100 \mathrm{nM}$, $1000 \mathrm{nM}$ ) and three replicates at each level were considered for spiked water samples. As listed in Table 1, the average recoveries were in the range of $98.6-106.4 \%$, and the RSD values were
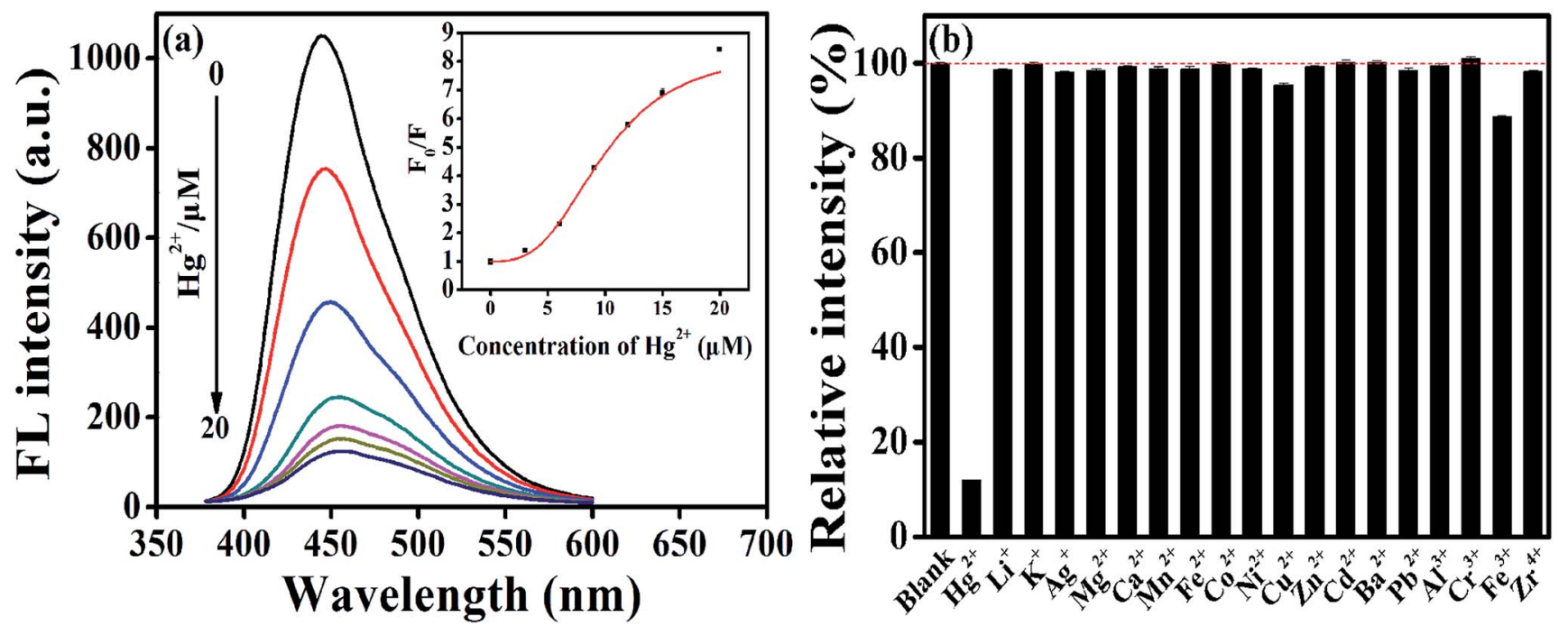

Fig. 2 (a) Fluorescent emission spectra at $450 \mathrm{~nm}$ of AA-CDs upon gradual addition of $\mathrm{Hg}^{2+}$ ions from 0 to $20 \mu M$. Inset: the dependence of $F_{0} / F$ on the concentration of $\mathrm{Hg}^{2+}$ ions $\left(F_{0}\right.$ and $F$ correspond to the fluorescence intensities of $A A-C D s$ in the absence and presence of $\mathrm{Hg}{ }^{2+}$ ions, respectively). (b) Selectivity of $A A-C D s$ to different metal ions (the concentration for all other metal ions is $60 \mu M$ ). Excitation wavelength is $360 \mathrm{~nm}$ and the excitation and emission slit width was $5.0 \mathrm{~nm}$. Blank corresponds to the fluorescence intensities of AA-CDs. 
Table 1 Determination of $\mathrm{Hg}^{2+}$ ions in environmental water samples using $A A-C D s$

\begin{tabular}{llrll}
\hline Samples & $\begin{array}{l}\text { Added } \\
(\mathrm{nM})\end{array}$ & $\begin{array}{l}\text { Found } \\
(\mathrm{nM})\end{array}$ & $\begin{array}{l}\text { Recovery } \\
(\%)\end{array}$ & $\begin{array}{l}\text { RSD } \\
(\%, n=3)\end{array}$ \\
\hline Tap water & 10 & 10.3 & 103.0 & 1.5 \\
& 100 & 103.5 & 103.5 & 2.3 \\
& 1000 & 1064.0 & 106.4 & 3.5 \\
Lake water & 10 & 10.3 & 103.0 & 2.1 \\
& 100 & 104.3 & 104.3 & 1.7 \\
& 1000 & 985.8 & 98.6 & 2.0 \\
River water & 10 & 10.1 & 101.0 & 2.5 \\
& 100 & 104.2 & 104.2 & 1.9 \\
& 1000 & 1020.2 & 102.0 & 2.1 \\
\hline
\end{tabular}

less than $3.5 \%$, testifying that the prepared AA-CDs could be used for the determination of $\mathrm{Hg}^{2+}$ ions in real waters.

\subsection{Turn-on sensor for Cys}

Turn-off mode for sensor has a potential risk in selectivity, namely some uncertain factors can cause fluorescence quenching. Typically, $\mathrm{Hg}^{2+}$ ions could interact with mercapto groups to form $\mathrm{Hg}-\mathrm{S}$ bonds, and accordingly, some mercapto compounds were commonly used in this study as a recovery agent, and it was found that with the addition of Cys into AACDs- $\mathrm{Hg}^{2+}$ system, the fluorescence quenched by $\mathrm{Hg}^{2+}$ could be dramatically recovered. The turn-on strategy greatly improves the selectivity for the detection of $\mathrm{Hg}^{2+}$ ions, by excluding the fluorescence quenching arisen from other uncertain factors.

And meanwhile, this principle could be applied to construct a fluorescence turn-on sensor for Cys detection. As illustrated in Fig. 3a, there is an increase in the fluorescence intensity at $450 \mathrm{~nm}$ by varying the Cys concentration from 0 to $10 \mu \mathrm{M}$, beyond which a sharp increase in the PL intensity is visible. A good linear relationship is found in the Cys concentration range of 0$700 \mathrm{nM}$, with the correlation coefficient $R$ of 0.99 and the detection limit of $30 \mathrm{nM}(\mathrm{S} / \mathrm{N}=3)$, which is comparable to those reported by other CDs sensing systems (Fig. S6 and Table S2†). To verify the selectivity of AA-CDs- $\mathrm{Hg}^{2+}$ system to Cys, the fluorescence responses of $\mathrm{AA}-\mathrm{CDs}-\mathrm{Hg}^{2+}$ to different amino acids were monitored and the results were presented in Fig. $3 \mathrm{~b}$ and S7. $\dagger$ It is clear to find that except for Cys, there are almost no significant changes in fluorescence intensity after adding other 19 kinds of amino acids or mixed amino acids solution, demonstrating that the AA-CDs- $\mathrm{Hg}^{2+}$ system has an excellent selectivity to Cys. It is worth noting that in some literatures, ${ }^{\mathbf{4 1 , 5 5}}$ the addition of histidine (His) could also recover the quenched fluorescence by $\mathrm{Hg}^{2+}$ ions, i.e. those reported sensors could not distinguish Cys and His. However, the developed AA-CDs- $\mathrm{Hg}^{2+}$ sensing system could clearly discriminate Cys and His in this study (Fig. 3b).

\subsection{Mechanism discussion for the "on-off-on" process}

It is well known that fluorescence emission of most CDs derives from the radiative recombination of excitons, which can be quenched by electron acceptors such as metal ions. ${ }^{49}$ Generally, the surface state has a significant impact on the band gap and excited states of CDs. With addition of $\mathrm{Hg}^{2+}$ ions, the oxygencontaining groups on the surface of AA-CDs could coordinate with $\mathrm{Hg}^{2+}$ ions to form complexes. Upon photo-excitation, the excited state of AA-CDs could relax its energy in the nonelectron transfer manner, leading to a substantial decrease of the fluorescence of AA-CDs, as supported by Fig. 4. The AA-CDs solution exhibits strong blue fluorescence, while an almost complete fluorescence quenching is observed by introducing $\mathrm{Hg}^{2+}$ ions to this solution. Upon addition of Cys to the solution of $\mathrm{AA}-\mathrm{CDs}-\mathrm{Hg}^{2+}$, the quenched fluorescence of $\mathrm{AA}-\mathrm{CDs}$ is recovered immediately. The fluorescence enhancement of $\mathrm{AA}-\mathrm{CDs}-\mathrm{Hg}^{2+}$ solution may be attributable to the formation of
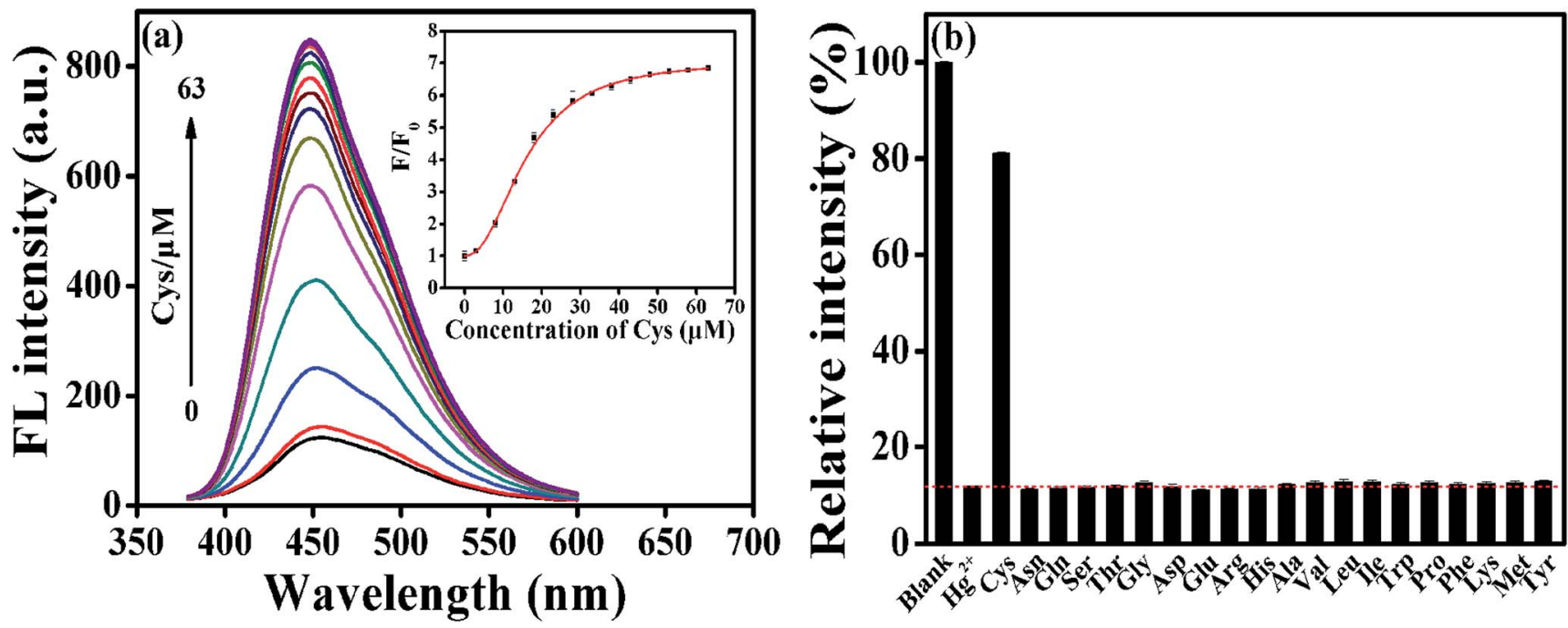

Fig. 3 (a) Fluorescent emission spectra at $450 \mathrm{~nm}$ of $\mathrm{AA}-\mathrm{CDs}-\mathrm{Hg}^{2+}$ upon gradual addition of $\mathrm{Cys}$ from 0 to $63 \mu \mathrm{M}$. Inset: the dependence of $F / F_{0}$ on the concentration of Cys. (b) Selectivity of AA-CDs- $\mathrm{Hg}^{2+}$ system to different amino acids (the concentration for all amino acids is $63 \mu \mathrm{M}$ ). $F$ and $F_{0}$ correspond to the fluorescence intensities of $\mathrm{AA}-\mathrm{CDs}-\mathrm{Hg}^{2+}$ in the presence and absence of Cys, respectively). Other conditions are same as in Fig. 2. 


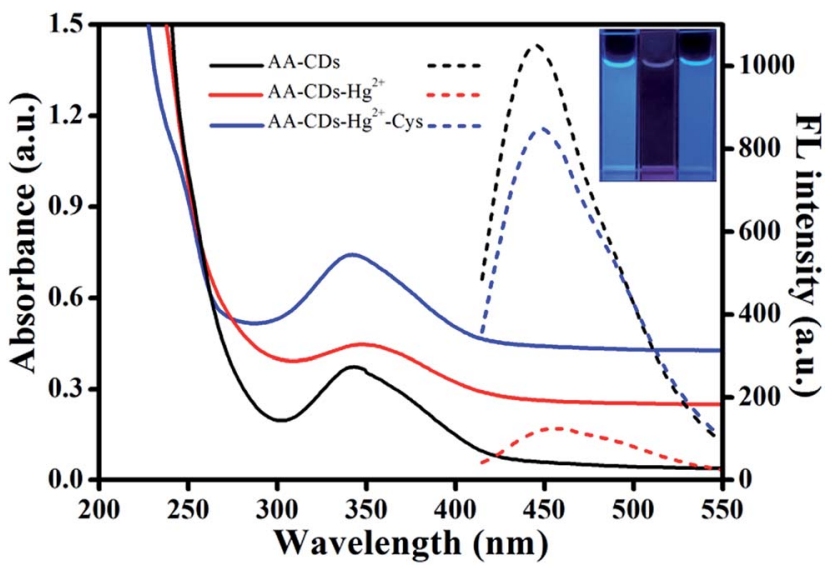

Fig. 4 UV-vis absorption (solid lines) and fluorescent emission spectra (dash lines) for $\mathrm{AA}-\mathrm{CDs}, \mathrm{AA}-\mathrm{CDs}-\mathrm{Hg}^{2+}, \mathrm{AA}-\mathrm{CDs}-\mathrm{Hg}^{2+}-\mathrm{Cys}$ systems. Inset: photographs of $\mathrm{AA}-\mathrm{CDs}, \mathrm{AA}-\mathrm{CDs}-\mathrm{Hg}^{2+}, \mathrm{AA}-\mathrm{CDs}-\mathrm{Hg}^{2+}-\mathrm{Cys}$ systems (from left to right) under UV lamp (365 nm).

$\mathrm{Hg}-\mathrm{S}$ bonds, which enables the removal of $\mathrm{Hg}^{2+}$ ions from the surface of AA-CDs. The UV-vis spectra were used to prove the aforesaid principle. Compared to AA-CDs (black solid in Fig. 4) absorption at $340 \mathrm{~nm}$, a slight red-shift occurs for AA-CDs- $\mathrm{Hg}^{2+}$ (red solid in Fig. 4) at $345 \mathrm{~nm}$, while the peak position of AACDs- $\mathrm{Hg}^{2+}$-Cys system (blue solid in Fig. 4) was almost the same as AA-CDs. During the experiment, no obvious absorbance was observed for $\mathrm{Hg}^{2+}$ ions, Cys and $\mathrm{Hg}^{2+}$-Cys in the wavelength range from 300 to $400 \mathrm{~nm}$, and accordingly, this slight red-shift should be attributed to the interactions between $\mathrm{Hg}^{2+}$ ions and functional groups of AA-CDs surface.$^{40}$ Further verification was followed by the TCSPC technology, which was used to study the exciton behaviors of the AA-CDs, AA-CDs- $\mathrm{Hg}^{2+}$ and AA-CDs$\mathrm{Hg}^{2+}$-Cys system, respectively. Under the excitation wavelength of $360 \mathrm{~nm}$ and emission wavelength of $450 \mathrm{~nm}$, an average lifetime can be achieved using eqn (3) in ESI. $\dagger$ The timeresolved fluorescence spectra were shown in Fig. $\mathrm{S} 8 \dagger$ and all detailed curve fittings were presented in Table S3. $\dagger$ The decay time of AA-CDs (Fig. S8a $\uparrow$ ) is $14.92 \mathrm{~ns}\left(\chi^{2}=0.976\right)$ with two components: $5.21 \mathrm{~ns}(c a .6 .87 \%)$ and $15.64 \mathrm{~ns}(c a .93 .13 \%)$. The decay time of AA-CDs- $\mathrm{Hg}^{2+}$ (Fig. S8b $\dagger$ ) is $9.93 \mathrm{~ns}\left(\chi^{2}=1.106\right)$ with two components: $4.13 \mathrm{~ns}$ ( $\mathrm{ca} .34 .13 \%)$ and $12.94 \mathrm{~ns}$ ( $\mathrm{ca}$. $65.87 \%$ ). The decay time of AA-CDs- $\mathrm{Hg}^{2+}$-Cys system (Fig. S8c $\dagger$ ) is $14.03 \mathrm{~ns}\left(\chi^{2}=1.014\right)$ with two components: $3.82 \mathrm{~ns}$ ( $c a$. $5.47 \%$ ) and $14.66 \mathrm{~ns}$ (ca. 94.26\%). The significant change in lifetime indicates an ultrafast $\mathrm{AA}-\mathrm{CDs} / \mathrm{Hg}^{2+}$ electron-transfer process and dynamic quenching process. ${ }^{56}$ Fluorescence quenching may attribute to non-radiative electron/hole recombination and annihilation through an effective electron or energy transfer process resulting from the strong electrostatic interaction and metal-ligand coordination between the AA-CDs and $\mathrm{Hg}^{2+}$ ions. ${ }^{57}$

The reversibility is considered to be significant for recycling of the indicator, especially for understanding the sensor mechanism..$^{20}$ However, previous studies illustrated that most sensor systems responded to $\mathrm{Hg}^{2+}$ ions irreversibly or the reversibility of the reported sensors had not been proved. In this study, the sequential addition of constant amounts of $\mathrm{Hg}^{2+}$ ions $(20 \mu \mathrm{M})$ and Cys $(63 \mu \mathrm{M})$ to the aqueous solution of AA-CDs gives rise to an alternative change in fluorescence intensity for the developed system. As exhibited in Fig. 5, the fluorescence recovery and quenching efficiency could reach as high as $90 \%$ after 10 cycles according to the original fluorescence value of AA-CDs, demonstrating excellent "on-off-on" reversibility. Here, it should be mentioned that the adding concentrations of $\mathrm{Hg}^{2+}$ and Cys were respective $20 \mu \mathrm{M}$ and $63 \mu \mathrm{M}$ in the first cycle. After ten cycles, the cumulative concentrations of $\mathrm{Hg}^{2+}$ and Cys were about $0.8 \mathrm{mM}$ and $2.6 \mathrm{mM}$.

\subsection{Imaging $\mathrm{Hg}^{2+}$ ions and Cys in living cells}

From above results, the prepared AA-CDs could be applied as fluorescent nanoprobes for sensing $\mathrm{Hg}^{2+}$ ions and Cys in aqueous solution with high sensitivity and selectivity. Benefited by their small size (generally several nanometers), CDs are easily internalized into the cells through caveolae-mediated endocytosis. ${ }^{5}$ Herein, we further investigate the feasibility for imaging $\mathrm{Hg}^{2+}$ ions and Cys in living biological systems using SMMC7721 cells as a model. The cytotoxicity of the prepared AACDs to SMMC-7721 cells was firstly evaluated by a standard MTT assay (in ESI $\dagger$ ), and the results revealed that no significant changes in cell viability and morphology were observed, implying excellent biocompatibility and low cytotoxicity (Fig. S9†). Subsequent experiments were carried out using AACDs as fluorescent nanoprobes for imaging intracellular $\mathrm{Hg}^{2+}$ ions and Cys in SMMC-7721 cells. As shown in Fig. 6a-c, by incubating the cells with AA-CDs $\left(200 \mu \mathrm{g} \mathrm{mL}{ }^{-1}\right)$ at $37^{\circ} \mathrm{C}(1 \mathrm{~h})$, a significant blue fluorescence from the intracellular region could be observed clearly (Fig. 6a). While, it is hard to find fluorescence signal from the cells incubated with exogenous $\mathrm{Hg}^{2+}$ ions $(100 \mu \mathrm{M})$ for another $1 \mathrm{~h}$ after incubating by AA-CDs (Fig. 6d). Furthermore, exogenous Cys $(150 \mu \mathrm{M})$ was used to incubate the living cells and no fluorescence could be observed (Fig. 6g). One can find in Fig. 6j that the cells incubated with AA-CDs- $\mathrm{Hg}^{2+}$ were further incubated for another $1 \mathrm{~h}$ at $37^{\circ} \mathrm{C}$

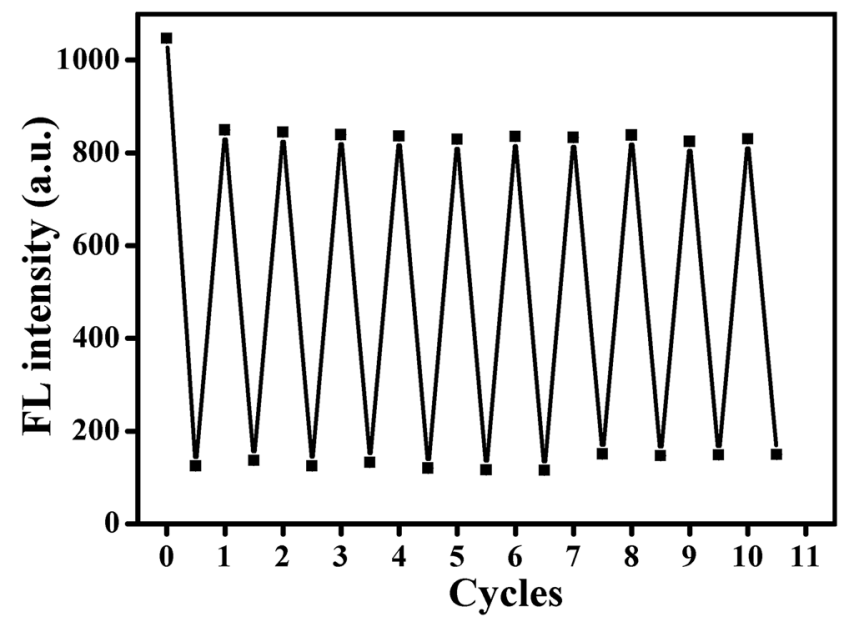

Fig. 5 The reversibility of AA-CDs by alternately adding $\mathrm{Hg}^{2+}$ ions and Cys in HEPES buffer. 

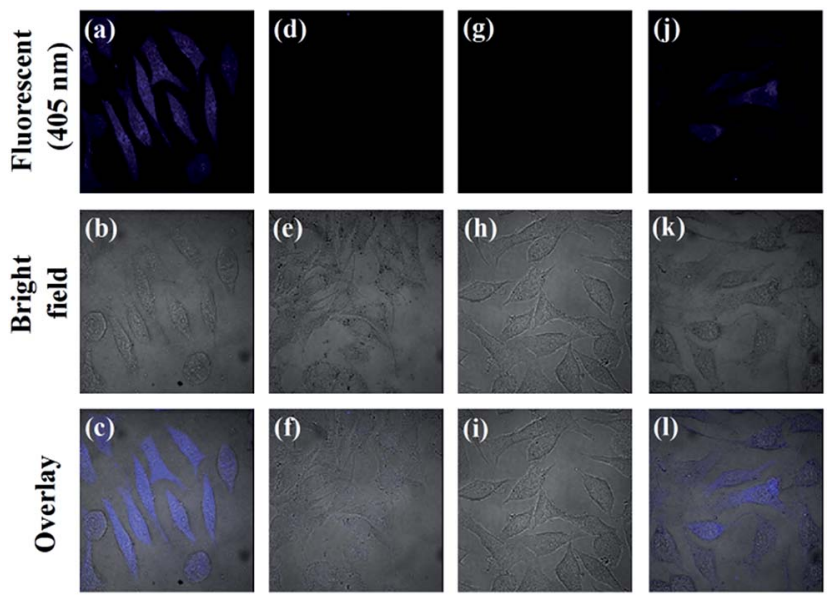

Fig. 6 Confocal laser scanning fluorescence microscopy images (a, $\mathrm{d}, \mathrm{g}$ and $\mathrm{j}, \lambda_{\mathrm{ex}}=405 \mathrm{~nm}$ ), corresponding bright-field images (b, e, h and $\mathrm{k}$ ), and the overlay of bright field and fluorescence images ( $c, f, i$ and $l$ ) for SMMC-7721 cells. $(a-c)$ Cells were incubated with AA-CDs for $1 \mathrm{~h}$ at $37^{\circ} \mathrm{C}$. (d-f) Cells were incubated with AA-CDs for $1 \mathrm{~h}$ at $37^{\circ} \mathrm{C}$ and then incubated with $\mathrm{Hg}^{2+}$ ions for 30 min at $37^{\circ} \mathrm{C}$. (g-i) Cells were incubated with Cys for $1 \mathrm{~h}$ at $37^{\circ} \mathrm{C}$. (j-l) Cells were incubated with AA$\mathrm{CDs}-\mathrm{Hg}^{2+}$ for $1 \mathrm{~h}$ at $37^{\circ} \mathrm{C}$ and then incubated with $\mathrm{Cys}$ for $1 \mathrm{~h}$ at $37^{\circ} \mathrm{C}$.

using Cys, the intracellular fluorescence was observed again from the confocal laser scanning microscopy z-stack images, indicating that the AA-CDs- $\mathrm{Hg}^{2+}$ system could be applied for imaging intracellular Cys.

\section{Conclusion}

In summary, using aconitic acid as a new carbon precursor, we prepared a kind of excellent fluorescent CDs by facile one-step microwave-assisted synthesis. The AA-CDs were completely water-soluble and the solution emitted excitation-independent, strong blue fluorescence with an absolute quantum yield of 45.1\%. The obtained AA-CDs were remarkably stable against light illumination, extreme $\mathrm{pH}$, and ionic strengths, and could serve as a promising fluorescence sensor. Without further surface chemical modification, $\mathrm{Hg}^{2+}$ ions could effectively quench the fluorescence of AA-CDs, meanwhile, introducing Cys into this AA-CDs- $\mathrm{Hg}^{2+}$ system could recover the quenched fluorescence. The developed on-off-on system has been proved to have good reversibility and consequently, and the fluorescence sensor system was designed for the detection of $\mathrm{Hg}^{2+}$ ions and Cys with excellent sensitivity and selectivity. Furthermore, the prepared AA-CDs have been demonstrated the reliability and feasibility for determining $\mathrm{Hg}^{2+}$ in environmental water samples and label-free imaging of $\mathrm{Hg}^{2+}$ ions and Cys in living cells. Benefited from above-mentioned advantages, it is believed that the aconitic acid derived CDs and the designed on-off-on sensor strategy will find their potential applications in environmental and biological fields.

\section{Conflicts of interest}

There are no conflicts to declare.

\section{Acknowledgements}

The authors are grateful to the financial support of the National Natural Science Foundation of China (No. 21675069 and 21527808) and the Fundamental Research Funds for the Central Universities (lzujbky-2017-111).

\section{References}

1 J. Tamayo, P. M. Kosaka, J. J. Ruz, A. San Paulo and M. Calleja, Chem. Soc. Rev., 2013, 42, 1287-1311.

2 G. L. Li, H. L. Fu, X. J. Chen, P. W. Gong, G. Chen, L. Xia, H. Wang, J. M. You and Y. N. Wu, Anal. Chem., 2016, 88, 2720-2726.

3 G. L. Li, W. H. Kong, M. Zhao, S. M. Lu, P. W. Gong, G. Chen, L. Xia, H. Wang, J. M. You and Y. N. Wu, Biosens. Bioelectron., 2016, 79, 728-735.

4 Q. T. Huang, X. F. Lin, J.-J. Zhu and Q.-X. Tong, Biosens. Bioelectron., 2017, 94, 507-512.

5 S. N. Baker and G. A. Baker, Angew. Chem., Int. Ed., 2010, 49, 6726-6744.

6 Y. F. Wang and A. G. Hu, J. Mater. Chem. C, 2014, 2, 69216939.

7 S. Y. Lim, W. Shen and Z. Q. Gao, Chem. Soc. Rev., 2015, 44, 362-381.

8 X. T. Zheng, A. Ananthanarayanan, K. Q. Luo and P. Chen, Small, 2015, 11, 1620-1636.

9 J. C. G. Esteves da Silvaand and H. M. R. Goncalves, Trends Anal. Chem., 2011, 30, 1327-1336.

10 K. Hola, Y. Zhang, Y. Wang, E. P. Giannelis, R. Zboril and A. L. Rogach, Nano Today, 2014, 9, 590-603.

11 K. A. S. Fernando, S. Sahu, Y. M. Liu, W. K. Lewis, E. A. Guliants, A. Jafariyan, P. Wang, C. E. Bunker and Y. P. Sun, ACS Appl. Mater. Interfaces, 2015, 7, 8363-8376.

12 Y. Q. Dong, J. H. Cai, X. You and Y. W. Chi, Analyst, 2015, 140, 7468-7486.

13 Y. Du and S. J. Guo, Nanoscale, 2016, 8, 2532-2543.

14 F. L. Yuan, S. H. Li, Z. T. Fan, X. Y. Meng, L. Z. Fan and S. H. Yang, Nano Today, 2016, 11, 565-586.

15 Y. H. Su, P. Chen, F. L. Wang, Q. X. Zhang, T. S. Chen, Y. F. Wang, K. Yao, W. Y. Lv and G. G. Liu, RSC Adv., 2017, 7, 34096-34103.

16 Y. M. Guo, L. F. Zhang, S. S. Zhang, Y. Yang, X. H. Chen and M. C. Zhang, Biosens. Bioelectron., 2015, 63, 61-71.

17 X. H. Gao, C. Du, Z. H. Zhuang and W. Chen, J. Mater. Chem. C, 2016, 4, 6927-6945.

18 Q. Li, Q. T. Huang, J.-J. Zhu, W.-G. Ji and Q.-X. Tong, RSC Adv., 2016, 6, 87230-87236.

19 M. Leermakers, W. Baeyens, P. Quevauviller and M. Horvat, Trends Anal. Chem., 2005, 24, 383-393.

20 E. M. Nolan and S. J. Lippard, Chem. Rev., 2008, 108, 34433480 .

21 S. Botasini, G. Heijo and E. Mendez, Anal. Chim. Acta, 2013, 800, 1-11.

22 G. Q. Chen, Z. Guo, G. M. Zeng and L. Tang, Analyst, 2015, 140, 5400-5443. 
23 H. Goncalves, P. A. S. Jorge, J. R. A. Fernandes and J. C. G. E. da Silva, Sens. Actuators, B, 2010, 145, 702-707.

24 H. L. Li, J. F. Zhai, J. Q. Tian, Y. L. Luo and X. P. Sun, Biosens. Bioelectron., 2011, 26, 4656-4660.

25 W. B. Lu, X. Y. Qin, S. Liu, G. H. Chang, Y. W. Zhang, Y. L. Luo, A. M. Asiri, A. O. Al-Youbi and X. P. Sun, Anal. Chem., 2012, 84, 5351-5357.

26 Y. M. Guo, Z. Wang, H. W. Shao and X. Y. Jiang, Carbon, 2013, 52, 583-589.

27 X. Y. Qin, W. B. Lu, A. M. Asiri, A. O. Al-Youbi and X. P. Sun, Sens. Actuators, B, 2013, 184, 156-162.

28 M. H. Lan, J. F. Zhang, Y. S. Chui, P. F. Wang, X. F. Chen, C. S. Lee, H. L. Kwong and W. J. Zhang, ACS Appl. Mater. Interfaces, 2014, 6, 21270-21278.

29 F. Y. Yan, Y. Zou, M. Wang, X. L. Mu, N. Yang and L. Chen, Sens. Actuators, B, 2014, 192, 488-495.

30 W. P. Wang, Y. C. Lu, H. Huang, A. J. Wang, J. R. Chen and J. J. Feng, Sens. Actuators, B, 2014, 202, 741-747.

31 Y. C. Lu, J. Chen, A. J. Wang, N. Bao, J. J. Feng, W. P. Wang and L. X. Shao, J. Mater. Chem. C, 2015, 3, 73-78.

32 Y. Wang, S. H. Kim and L. Feng, Anal. Chim. Acta, 2015, 890, 134-142.

33 L. B. Li, B. Yu and T. Y. You, Biosens. Bioelectron., 2015, 74, 263-269.

34 Y. X. Hou, Q. J. Lu, J. H. Deng, H. T. Li and Y. Y. Zhang, Anal. Chim. Acta, 2015, 866, 69-74.

35 Y. Liang, H. Zhang, Y. Zhang and F. Chen, Anal. Methods, 2015, 7, 7540-7547.

36 A. Gupta, A. Chaudhary, P. Mehta, C. Dwivedi, S. Khan, N. C. Verma and C. K. Nandi, Chem. Commun., 2015, 51, 10750-10753.

37 F. Y. Yan, D. P. Kong, Y. M. Luo, Q. H. Ye, J. J. He, X. F. Guo and L. Chen, Microchim. Acta, 2016, 183, 1611-1618.

38 J. L. He, H. R. Zhang, J. L. Zou, Y. L. Liu, J. L. Zhuang, Y. Xiao and B. F. Lei, Biosens. Bioelectron., 2016, 79, 531-535.

39 W. J. Tang, Y. Wang, P. P. Wang, J. W. Di, J. P. Yang and Y. Wu, Microchim. Acta, 2016, 183, 2571-2578.

40 L. Zhou, Y. H. Lin, Z. Z. Huang, J. S. Ren and X. G. Qu, Chem. Commun., 2012, 48, 1147-1149.

41 J. Hou, F. S. Zhang, X. Yan, L. Wang, J. Yan, H. Ding and L. Ding, Anal. Chim. Acta, 2015, 859, 72-78.
42 Z. Li, Y. Wang, Y. N. Ni and S. Kokot, Sens. Actuators, B, 2015, 207, 490-497.

43 M. H. Lan, J. F. Zhang, Y. S. Chui, H. Wang, Q. D. Yang, X. Y. Zhu, H. X. Wei, W. M. Liu, J. C. Ge, P. F. Wang, X. F. Chen, C. S. Lee and W. J. Zhang, J. Mater. Chem. B, 2015, 3, 127-134.

44 J. H. Deng, Q. J. Lu, Y. X. Hou, M. L. Liu, H. T. Li, Y. Y. Zhang and S. Z. Yao, Anal. Chem., 2015, 87, 2195-2203.

45 F. Y. Yan, D. C. Shi, T. C. Zheng, K. Y. Yun, X. G. Zhou and L. Chen, Sens. Actuators, B, 2016, 224, 926-935.

46 T. Liu, N. Li, J. X. Dong, H. Q. Luo and N. B. Li, Sens. Actuators, B, 2016, 231, 147-153.

47 S. M. Lu, D. Wu, G. L. Li, Z. X. Lv, Z. L. Chen, L. Chen, G. Chen, L. Xia, J. M. You and Y. N. Wu, RSC Adv., 2016, 6, 103169-103177.

48 M. J. Krysmann, A. Kelarakis, P. Dallas and E. P. Giannelis, J. Am. Chem. Soc., 2012, 134, 747-750.

49 S. J. Zhu, Q. N. Meng, L. Wang, J. H. Zhang, Y. B. Song, H. Jin, K. Zhang, H. C. Sun, H. Y. Wang and B. Yang, Angew. Chem., Int. Ed., 2013, 52, 3953-3957.

50 Y. Q. Dong, H. C. Pang, H. B. Yang, C. X. Guo, J. W. Shao, Y. W. Chi, C. M. Li and T. Yu, Angew. Chem., Int. Ed., 2013, 52, 7800-7804.

51 D. Qu, M. Zheng, L. G. Zhang, H. F. Zhao, Z. G. Xie, X. B. Jing, R. E. Haddad, H. Y. Fan and Z. C. Sun, Sci. Rep., 2014, 4, 5294.

52 M. Zheng, Z. G. Xie, D. Qu, D. Li, P. Du, X. B. Jing and Z. C. Sun, ACS Appl. Mater. Interfaces, 2013, 5, 13242-13247.

53 I. Costas-Mora, V. Romero, I. Lavilla and C. Bendicho, Anal. Chem., 2014, 86, 4536-4543.

54 U.S. Environmental Protection Agency, National Primary Drinking Water Regulations, Washington, D.C, 2009, EPA 816-F-09-004.

55 F. Pu, Z. Z. Huang, J. S. Ren and X. G. Qu, Anal. Chem., 2010, 82, 8211-8216.

56 Y. P. Zhu, T. Y. Ma, T. Z. Ren and Z. Y. Yuan, ACS Appl. Mater. Interfaces, 2014, 6, 16344-16351.

57 B. Y. Han, J. P. Yuan and E. K. Wang, Anal. Chem., 2009, 81, 5569-5573. 